EPJ Web of Conferences 98, 04006 (2015)

DOI: $10.1051 /$ epjconf/ 20159804006

C Owned by the authors, published by EDP Sciences - SIF, 2015

\title{
Electricity generation by intermittent sources
}

\author{
F. WAGNER
}

Max-Planck-Institut für Plasmaphysik - Greifswald, Germany

\begin{abstract}
Summary. - This paper deals with the production of electricity by wind and photovoltaic (PV) power mostly in Germany. The German data of 2012 are scaled to a $100 \%$ supply of the electricity consumption by renewable sources. Wind and PV power are mixed in a ratio which minimises back-up energy. The $100 \%$, optimal mix data are used to identify the powers to be installed, the accumulating backup and surplus energies, the size of storage to replace thermal back-up power, the possibilities of demand-side-management, and the specific $\mathrm{CO}_{2}$ production. The benefits of using an EU-wide field of renewable energies (RES) instead of the national one are quantified and the interconnection capacities specified. Finally, the costs of installing RES are discussed. The conclusion is that a $100 \%$ supply by RES may not be meaningful. Large-scale supply by RES alone has deficiencies and it will remain a major task for science and technology to either improve such a system or find a suitable replacement.
\end{abstract}

\section{1. - Introduction}

This paper deals with the production of electricity by wind and photovoltaic power. With these technologies, electricity is produced via the kinetic energy of the wind field transferred into electricity using wind convertors [1] and via the energy of solar radiation by the photoelectric effect [2]. With these technologies, the electricity production is intermittent in its nature because the primary energies — wind and solar radiationvary in time and cannot be predicted precisely. In this paper, we specifically address issues which originate from the variability of these electricity sources.

This is an Open Access article distributed under the terms of the Creative Commons Attribution License 4.0, which permits unrestricted use, distribution, and reproduction in any medium, provided the original work is properly cited. 


\section{EPJ Web of Conferences}

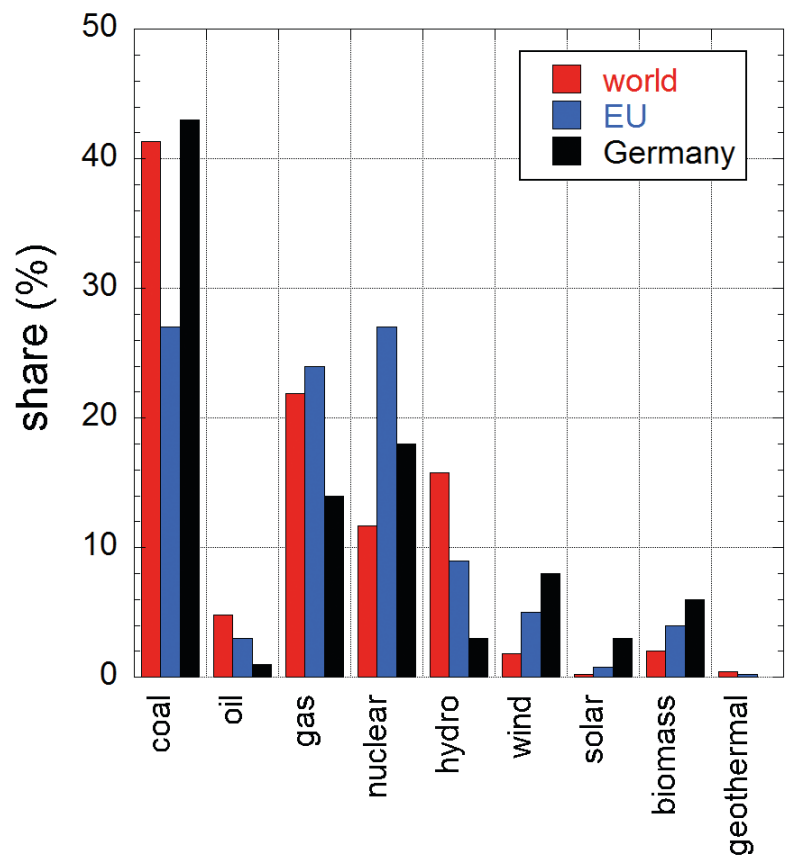

Fig. 1. - The share of fossil, nuclear and renewable energy sources for electricity production in 2011 is shown for three regions: the world, Europe and Germany.

There is a limited number of techniques for producing electricity:

- the use the chemical energy stored in coal, oil and gas and burning fossil fuels;

- using nuclear energy which can be released by fission of uranium [3] or thorium [4] or by fusion of light elements like deuterons and tritons [5];

- using renewable energies (RES) like hydro, geothermal [6], solar thermal, photovoltaic, onshore and offshore wind [1] and biomass [7].

Figure 1 shows the composition of the primary sources for electricity production worldwide, in Europe and in Germany. The three regions have a similar splitting. The technology of choice is by far burning of fossil fuels with a share which is larger than $60 \%$. Here, coal is the dominant fuel. To a large extent its use is responsible for the "global warming problem" [8]. The scalable RE forms wind and photovoltaic (PV) power sum up globally to about $2 \%$. Its presently minor role clearly shows how tremendous the task is to implement RE technology worldwide in order to avoid further pollution of the atmosphere by $\mathrm{CO}_{2}$ emission. Nuclear energy plays a large role in Europe; its replacement by RES is $\mathrm{CO}_{2}$-neutral. The most advanced country in the use of renewable energies is Germany.

Electricity is the most versatile form of energy because it can be transformed into other forms without large losses providing services like mechanical power, communication, mobility, light, heat, and other forms. Electricity can also easily be transported over large 


\section{LNES 2014}

distances. It has, however, a crucial disadvantage at present: it cannot be stored in large scales. We are used to the fact that electricity is available whenever needed, day and night without any limits and restrictions. The consequence is that electricity has to be produced exactly at the rate it is consumed. In order to ensure constant grid voltage and frequency, sophisticated grid technology and operation and distribution logistics have been realised in the industrialised world.

This convenient situation may change in the future out of various reasons. The dominant ones are the finite availability of fossil fuels and - much before the supply finally comes to an end - the critical environmental consequences of their use. Fossil sources can be made "clean" by carbon capture and sequestration (CCS) or be replaced by clean ones like nuclear power in the form of fission and fusion. CCS is not free of environmental risks and the technology is not ready for large-scale penetration. Fission has to be based on breeder technology with fast neutrons but the society might disapprove of this technology. Fusion will not be ready before mid-century. Therefore, only RES are a realistic option at present.

But also the use of RES has restrictions. Geothermal energy is restricted to special geological conditions and plays a minor role even in Japan despite the many hot springs in this country. The use of biomass is critical and its justification to be considered in detail [9]. Many crops and processes applied today have a marginal positive energy and negative $\mathrm{CO}_{2}$ balance and are only applied because of massive lobbying and subsidy. The overarching problem of biomass for electricity generation is that a piece of land, covered by $\mathrm{PV}$ panels produces a factor of $>100$ more electricity than the alternative use via biomass could provide [10].

Solar power has two branches, solar thermal and PV. Solar thermal electricity production requires direct light which can be focussed onto a collector. This is not economically viable in northern zones where, on the other hand, the consumer is located. This technology applied to feed Europe requires large grids starting in northern Africa and this may be one of the reasons why the partners of the DESERTEC project scaled down their objectives.

What remains are wind and PV power which can be scaled to large installed powers if the necessary land area and funding are allocated. Germany as a typical northern industrialised country employs these technologies (see fig. 1) and succeeded in an installed power in 2014 which nearly matches the peak demand of the German consumer. We will use the experience of Germany being a large energy consumer located in the middle of the European grid. We will try to assess the use of RES in large scales, specifically the consequences of intermittent supply into the grid which has to maintain the exact balance between demand and supply for every moment. In addition, the German electricity providers publish excellent data of consumption and electricity production by RES with good time resolution $(15 \mathrm{~min})$ [11]. These data will be used to scale to even higher installed powers up to the limit of a $100 \%$ supply by wind and PV. This limit may not be realistic but it is well defined and allows to portrait the features of a future supply by intermittent sources. 


\section{EPJ Web of Conferences}

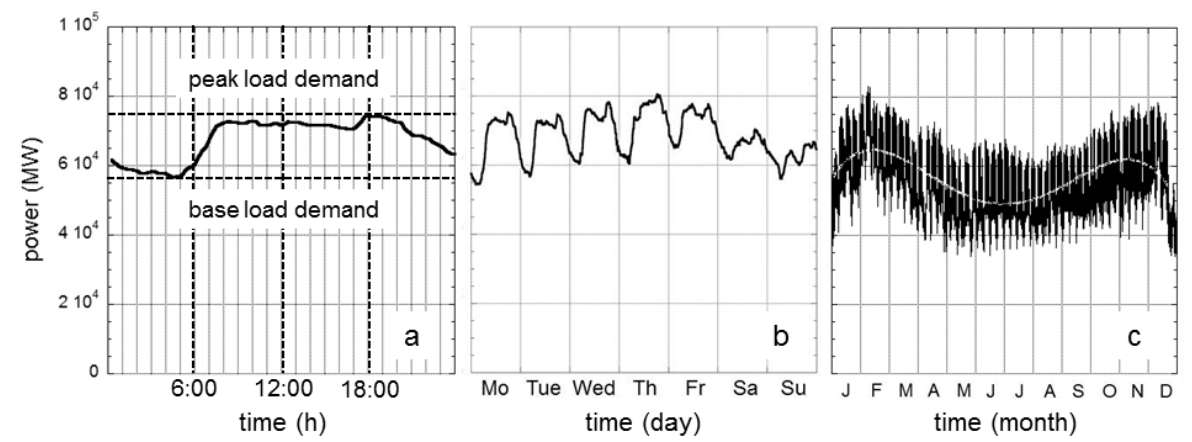

Fig. 2. - The load is plotted for a) a day (Tuesday, 21.1.2012), b) a week (30.1.-5.2.2012) and c) a year (2012). The white curve in c) is a polynomial fit to the data and guides the eye. Peak and base load are indicated in a).

\section{2. - Electricity production and consumption $\left({ }^{1}\right)$}

Figure 2a shows the load, equivalent to consumption, exactly matched by supply, for a winter day in Germany. There is continuous electricity demand during the day with a lower level during the night - defining the base load. The maximum in demand (peak load) happens at about 18:00 when the economic activities are still ongoing but also private consumption increases. From this graph the annual electricity consumption of Germany can be quickly assessed. The day average power is about $65 \mathrm{GW}$ leading to an annual demand of about $570 \mathrm{TWh}$. Figure $2 \mathrm{~b}$ again shows the load but during a winter week. During workdays, the variation follows a similar pattern, is slow and rather predictable; during the weekend, the demand is reduced. Figure 2c shows finally the load curve during the year 2012 along with a fit to the data. The fluctuations are caused by the weekly cycle. The diurnal cycle is not resolved. The fit shows that the electricity requirement in Germany is largest in the winter months (but sharply drops during Christmas season).

Wind power is produced onshore (Won) and offshore (Woff). The German wind power 2012 is plotted in fig. 3 for onshore (fig. 3a) and offshore (fig. 3b) wind. German $\mathrm{PV}$ power of 2012 is shown in fig. 3c. The installed power levels in 2012 of $31 \mathrm{GW}$ onshore, $164 \mathrm{MW}$ offshore and $32 \mathrm{GW} \mathrm{PV}$ are shown as horizontal lines in fig. 3. These are the installed capacities at the end of 2012. The data shown in fig. 3 are corrected for the continuous growth of production capacity during the year and represent a situation with constant installed powers corresponding to those at the end of 2012.

Electricity production fluctuates in all three cases. In case of offshore wind, the amplitude is limited at the level of the installed power. This has partly to do with the rather central location of the still small offshore wind parks of Germany in $2012[12,13]$.

$\left(^{1}\right)$ The German electricity data are taken from the sources as given in ref. [11]. 


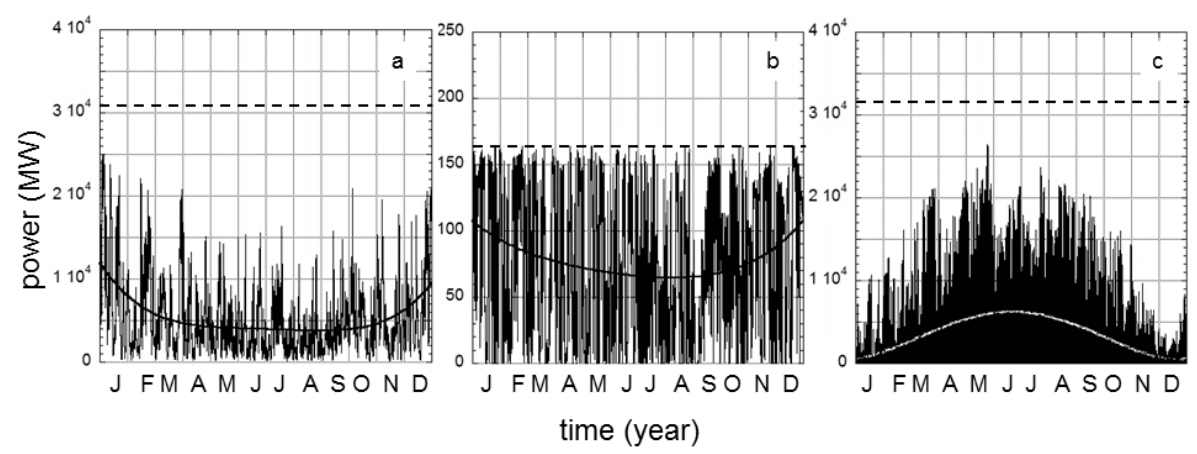

Fig. 3. - Onshore (a), offshore (b) and photovoltaic (c) power for 2012. The curves are polynomial fits and guide the eye. The dashed lines denote the installed power levels at the end of 2012 . The three time series are corrected for increasing capacity during the year and correspond to the installed power at the end of the year.

The dominant reason is, however, the higher wind velocity on sea which causes wind convertors to frequently operate at constant nominal power between rated output speed and cut-out wind speed. This is different in case of onshore wind where the turbines operate mostly in a wind velocity range where the power $p \propto v_{\text {wind }}^{3}$ [14]. The fits to the time series show that both Won and Woff have larger contributions in winter whereas PV contributes mostly during the summer months.

Figure 4a presents the load, onshore wind and on top of it PV for a week in winter and fig. $4 \mathrm{~b}$ for one in summer. What we already know is shown once more - load and onshore wind powers are larger in winter, PV power is larger in summer. The time series characteristics of wind is erratic whereas the one of PV is periodic, with varying amplitude, however. Favourably, PV contributes during the day when the demand is maximum. In 2012, wind and PV are still insufficient to meet the load. The gap (black

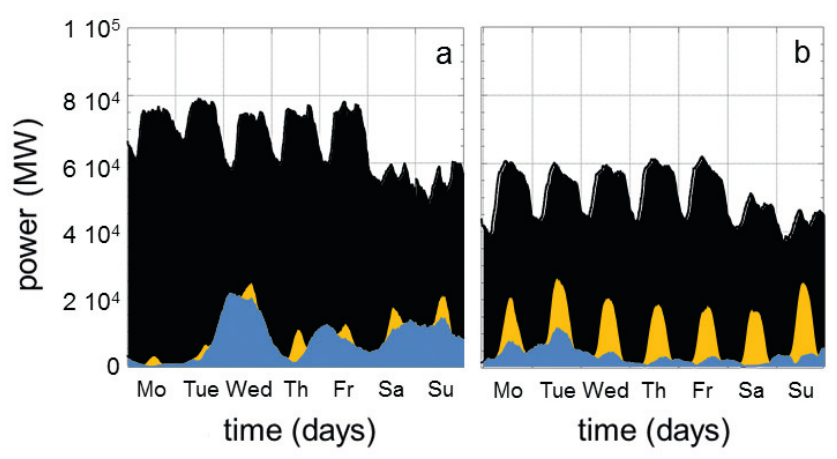

Fig. 4. - Load (black), wind (blue) and photovoltaic power (yellow) for a week in winter (13.19.2.2012) and one in summer (6.-12.8.2012). 


\section{EPJ Web of Conferences}

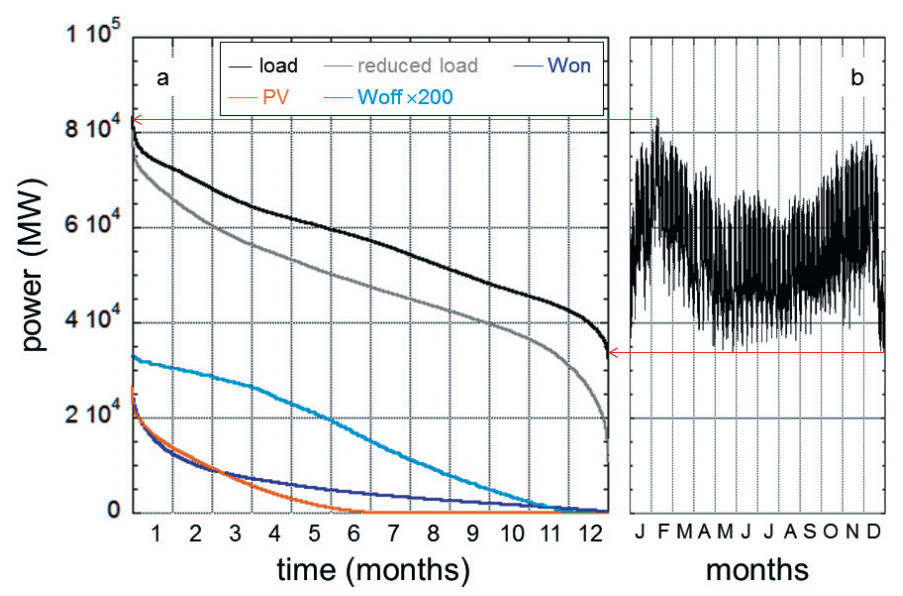

Fig. 5. - a) Annual duration curves of load, reduced load (defined in the text), onshore, offshore and photovoltaic power for 2012. The offshore wind power values are multiplied by 200 . b) Load of 2012 to demonstrate the construction of the annual duration curve indicating the position of the highest and the lowest power value.

areas in fig. 4) is filled by residual back-up power presently based on thermal power stations (fossil and nuclear).

Important parameters to assess specifically the economic operation of a system are the full load hours $(f l h)$ or the capacity factor $(c f)$. $f l h$ is defined as ratio of annually produced energy to installed power and $c f=f l h /($ hours of the year), $8784 \mathrm{~h}$, in case of the leap year 2012. For this year, $f l h$ and $c f$-values are $1858 \mathrm{~h}$ and 0.21 for Won, $4134 \mathrm{~h}$ and 0.47 for Woff and $966 \mathrm{~h}$ and 0.11 for PV. These two parameters vary from year to year. The advantage of offshore wind and the disadvantage of photovoltaic power are obvious. flh and $c f$ are also used to characterise the operation of conventional power stations either individual power plants or the collective system providing an average value. To compare with, for $2012 f l h=6020 \mathrm{~h}$ and $c f=0.69$ for the back-up systems providing the balancing power. The electricity costs $c$ are related to these parameters via $c=\alpha / c f+\beta O P[15]$ with $O P$ being the operational costs (fuel, maintenance) and $\alpha$ and $\beta$ are system parameters. For wind and PV systems, $\beta$ is close to zero because there are no fuel costs. In this case, the costs depend strongly on $c f$ or $f l h$, respectively.

Another important way to look at power and power distribution is the annual duration curve. Plotted are the power levels of the load or a source, respectively, which occur during a year but the values are not ordered chronically (as in figs. 2 and 3) rather in falling sequence. Figure 5 shows how a duration curve is constructed for the load starting with peak and ending with the minimum power value. Figure 5a shows the duration curves for the load, Won, Woff and PV. Woff, still at low level, is multiplied by a factor of 200 to allow comparison. The duration curves indicate for how long the load or a specific source stays above a defined level. The load stays above the base load 

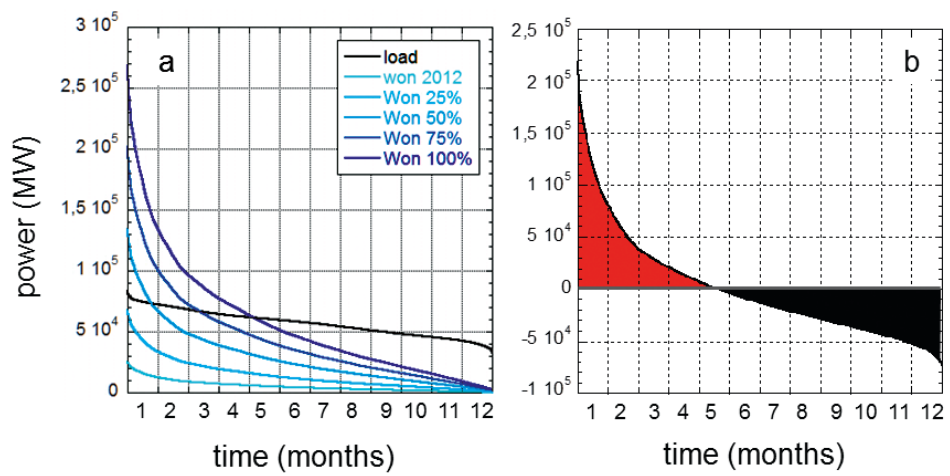

Fig. 6. - a) Annual duration curves of the load and onshore wind starting from the 2012 level and scaled in steps up to the $100 \%$ case where the wind energy (area beneath the Won $100 \%$ curve) agrees with the total annual electricity consumption (area beneath the load curve). b) Annual duration curve of surplus and back-up (negative) powers; the areas are identical for the $100 \%$ case.

level for the whole year - this is trivial and corresponds to the base load definition. PV stays above zero for half a year only because it is only available during the day. Onshore wind power is available for more than $50 \%$ of the installed power for only a month. For offshore wind power, because of its more steady nature, this quality is maintained for about half a year. The areas beneath the curves correspond to the annual energy demand in case of the load (about $570 \mathrm{TWh}$ for Germany, as we have seen) or the annual energy produced by one of the sources, respectively.

It is important to note that the shapes of load and of the intermittent sources do not fit. Specifically for Won and PV, the match is very bad. These curves have more of a hyperbolic shape whereas the load, which should be perfectly matched, shows a more-or-less linear slope. This lack of agreement leads to the major problem in the use of intermittent sources as indicated in fig. 6. Figure 6a shows annual duration curves of the load as reference and the onshore wind power of 2012 as starting point. Wind power is then scaled up in steps up to the annual production of wind electricity matching the annual consumption - up to the $100 \%$ case. Large power installations are necessary to produce the energy target. In the example of fig. 6a nearly up to $300 \mathrm{GW}$ of onshore wind power have to be installed. At high power levels Won (100\%) is above the peak and at low power levels it is below the base load. This indicates the production of surplus power and the need of back-up power, respectively. Figure $6 \mathrm{~b}$ plots surplus (for $P_{W o n}>P_{\text {load }}$ ) and, negative, the back-up power (for $P_{W o n}<P_{\text {load }}$ ) in the form of a duration curve. We see that in this artificial case (only Won considered), surplus is produced at the high power level of wind generation for about 4.5 months whereas back-up power - of course, at the lower power level of the load - is needed for the rest, for 7.5 months. The red and black areas in fig. 6b represent the produced annual surplus and needed back-up energy. For the $100 \%$ case of fig. 6 , surplus energy and back-up energy are the same and, 


\section{EPJ Web of Conferences}
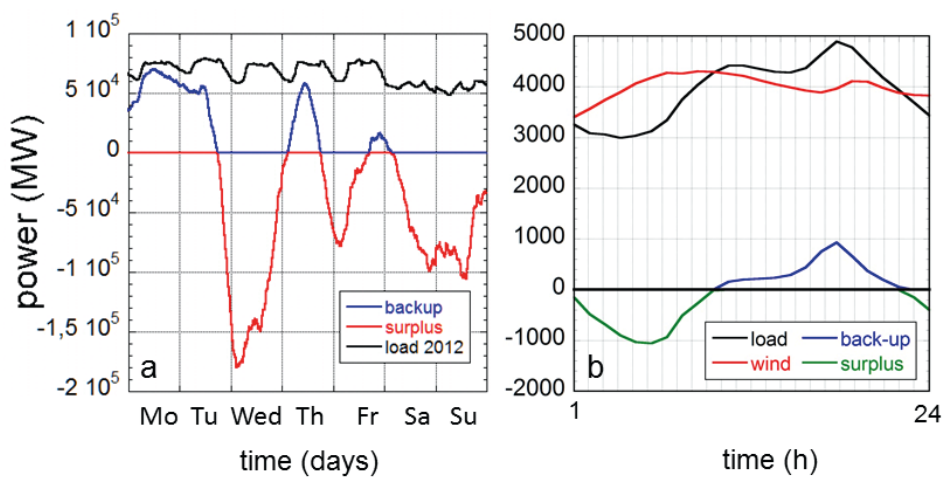

Fig. 7. - a) Load, back-up and surplus (negative) power for the week 13.2-20.2.2012. b) Load, wind (on + offshore), surplus (negative) and back-up power for Denmark for 21.12.2013.

in this specific case, they are about $1 / 3$ of the annual demand - quite a large fraction. Whereas the peak load is $83 \mathrm{GW}$ (see fig. 5a), the peak power of the back-up system is slightly lower, $73 \mathrm{GW}$ (see fig. $6 \mathrm{~b}$ ). There is some saving in thermal back-up power but not more than $12 \%$. Later, we will carry out analyses like this more realistically with a mix of wind and PV and in more detail.

The objective of the $100 \%$ case is ultimately, to accept surplus and to put it into a storage to deliver the balance power and making thus the thermal back-up systems redundant. Figure 7a shows the load, the back-up power and the surplus power (negative) for one week in 2012 but with onshore wind as the only RE source scaled to the $100 \%$ limit. Surplus and back-up powers follow each other in a sequence of typically one or two days. Back-up power stays beneath the load whereas surplus can reach high power values.

In Denmark with about $33 \%$ annual share of wind energy, the installed power is large enough to allow days which correspond to the $100 \%$ case. Such a case was realised Dec. 21st, 2013 and is shown in fig. $7 \mathrm{~b}\left({ }^{2}\right)$. Plotted are the load, and the sum of on- and offshore wind along with the difference between these two curves separated for the positive period - load $>$ wind power (back-up needed), and the negative one - load $<$ wind power (negative, surplus produced). Integrally, consumption and wind production are about the same with 94 and $96 \mathrm{GWh}$, respectively. The integral back-up as defined above is $4.5 \mathrm{GWh}$ whereas the surplus is $6.6 \mathrm{GWh}$. As electricity is generated in Denmark in co-production with heat (CHP), the thermal power stations produced $47 \mathrm{GWh}$, much more than needed for back-up giving rise to a net-export of electricity of 49 GWh.

$\left({ }^{2}\right)$ The data for this figure have been provided by P.-F. Bach. 


\section{LNES 2014}

\section{3. - Assumptions for the scenario studies}

In the following we will scale the German wind and PV data of 2012 to higher power levels up to the $100 \%$ case as described above [16]. Before doing this, we have to clarify and to justify the external conditions for this extrapolation. The objective is to meet the demand with RES only - hydropower, wind and PV. Other renewable forms like solar thermal and geothermal are not considered as they can only play a minor role. Nuclear energy, though $\mathrm{CO}_{2}$-free in electricity generation, is discarded out of societal acceptance reasons. Biomass, partially $\mathrm{CO}_{2}$-free $\left({ }^{3}\right)$, is also not considered $\left({ }^{4}\right)$ because its potential is limited (limited to waste in the frame of generation-2 biomass [9]) and in my view, it will be primarily used for transportation in those sectors which cannot use batteries like aviation and heavy transportation. As a $100 \%$ supply by RES will be realised in many years the assumptions of electricity savings are of importance. Savings represent of course the best measure to cope with all energy-related critical issues. The experience up to now shows, however, how difficult it is to effectively save electricity. The electricity consumption of Germany grew by about $0.5 \%$ per year over the last 20 years. Electricity consumption might drop in the long run when the German population decreases - if this indeed happens. Other developments will lead to an increase in electricity consumption. To reduce the national $\mathrm{CO}_{2}$ output, primary energy has to be saved in the first step. The corresponding measures often require the use of electricity. An example is the use of heat pumps to reduce the use of fossil fuels for space heating. In the future electric cars are expected to dominate individual transportation. The German volume of traffic would require more than $100 \mathrm{TWh}$ electricity, about $20 \%$ of the present electricity consumption. Another issue which might gain importance is the need to cool offices in large cities as it is the case already nowadays in southern countries. This could happen when also at our latitude the average temperature rises due to global warming. In summary, for our projections we keep the electricity demand of Germany constant (because we do not know better).

As we assume a constant hydro-electricity power over the year at the present level, wind and PV power have to supplement the difference between load and hydro-power. We call this difference the reduced load and it is the actual target for the $100 \%$ case. Figure 8 is a graphical representation of the transformation of the electricity supply system from the present German conditions (left column) to a future one (right). The net electricity production in 2012 is actually 530 TWh. Hydro-electricity contributed with $21 \mathrm{TWh}$. The reduced load and target of the extrapolation is set to $500 \mathrm{TWh}$. The contributions of other sources are given in fig. 8. In the future, at constant consumption, only hydro-electricity, wind and PV power will contribute. As wind and PV power are

$\left({ }^{3}\right)$ Biomass is partially $\mathrm{CO}_{2}$ free because carbon is cycled in the process of growing and burning or using. On the other hand, fuel is needed for transportation of biomass and other greenhouse gases are set free via the use of fertilizers.

$\left.{ }^{4}\right)$ In sect. 9 we consider the limits for RES use and we will include the use of biomass in this discussion. 


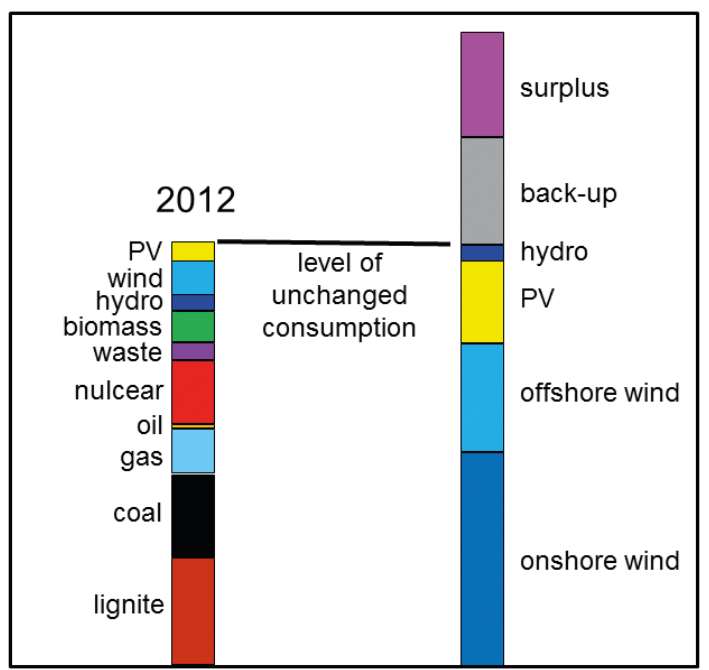

Fig. 8. - Composition of electricity production in Germany in 2012 and in the future at invariant annual consumption. Hydroelectricity is assumed constant. The replacement of dispatchable by intermittent sources leads to surplus and back-up energies.

not available in a controlled manner surplus energy incurs and balancing power from a back-up system is necessary. Surplus energy and back-up energy are identical in the $100 \%$ case. They are added in fig. 8 on the right-side in scale. Their share and amount will be discussed in the following.

Another issue to be clarified are the shares of wind and PV and the share between onshore and offshore wind power. The different time series of wind and PV power - one being erratic and the other one periodic - and their different match to the seasonal or diurnal variation of the load, respectively, allow determining an optimal mix of wind and $\mathrm{PV}$ power. The optimisation target is the minimisation of back-up energy and therefore of the $\mathrm{CO}_{2}$ output. Figure 9a shows the annual back-up energy $E_{\text {back-up normalised to }}$ the reduced load versus the energy produced by $\mathrm{PV}$ power $E_{\mathrm{PV}}$ normalised in the same form. The curves are obtained for the $100 \%$ case for Germany and three other European countries (Spain, France, Czech Republic) as well as for the superimposed RE field of 4 European countries. The EU-wide situation will be discussed in sect. $\mathbf{8}$.

There is a shallow minimum in $E_{\text {back-up }}$ around a PV energy share of not more than typically $20 \%$. $E_{\text {back-up }}$ rises slightly without PV and strongly, when the reduced load would be met exclusively by PV power. We define the PV share now at $20 \%$ according to the optimal condition. Then the mix is well defined though we do not expect that the build-up of RES is governed by such a consideration specifically as the market participants are largely different for wind or PV, respectively. With the optimum mix, all side effects, which we discuss in the following, will be minimal and will be larger off this optimum. 
LNES 2014

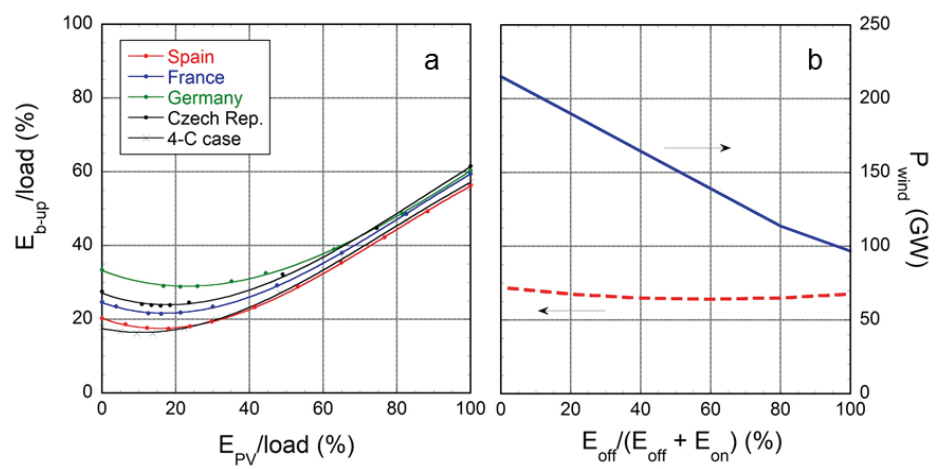

Fig. 9. - a) Back-up versus photovoltaic energy for the $100 \%$ case. Both energies are normalised to the respective annual consumption. Results are shown for four EU countries along with the composed case (4-C case, see main text). b) Dashed curve: normalised back-up energy versus the offshore wind power share for the $100 \%$ case. Solid curve: installed wind power versus the offshore wind power share.

The proper mix between onshore and offshore wind cannot be decided by a similar argument. Figure $9 \mathrm{~b}$ plots $E_{\text {back-up }}$ normalised against the load versus the offshore wind energy fraction. There is basically no dependence. A strong difference is, however, for the total wind power to be installed as shown also in fig. 9b which is maximal for exclusively onshore wind and reduced when offshore wind is added according to the ratio of $c f$ or $f l h$-values, respectively. As the final mix will be determined by legislative measures or economic considerations, which we cannot anticipate, we set the offshore wind contribution arbitrarily to $1 / 3$ of the total wind one. The following sections describe the properties of idealistic cases because losses and transformation efficiencies are not considered.

\section{4. - The $100 \%$, optimal mix case for Germany}

Figure 10a depicts the variation of various energies (produced energy, back-up and surplus energy, left axis) and the grid power (right axis) versus the installed RE power. Without RES, the back-up system has to produce the full reduced energy needed of $500 \mathrm{TWh}$. The grid power is at the level of the maximum load, $83 \mathrm{GW}$. The produced $\mathrm{RE}$ contribution grows linearly with $\mathrm{RE}$ power in the model. This is not realistic, because with increasing number of installations, lower quality sites have to be accepted. In reality, this curve will be bent toward saturation at high level. Surplus energy accrues as soon as the RE power increases above the load. This is also the moment where the grid power increases. At this point, wind and PV power contribute with about $40 \%$ to the total demand. This could be seen as a limit up to which RES can be integrated in Germany without major difficulties.

Surplus and back-up energies meet at $100 \%$ supply by RES. The level of both is $131 \mathrm{TWh}, 26 \%$ of the demand. A further increase of RES beyond the $100 \%$ case would 


\section{EPJ Web of Conferences}
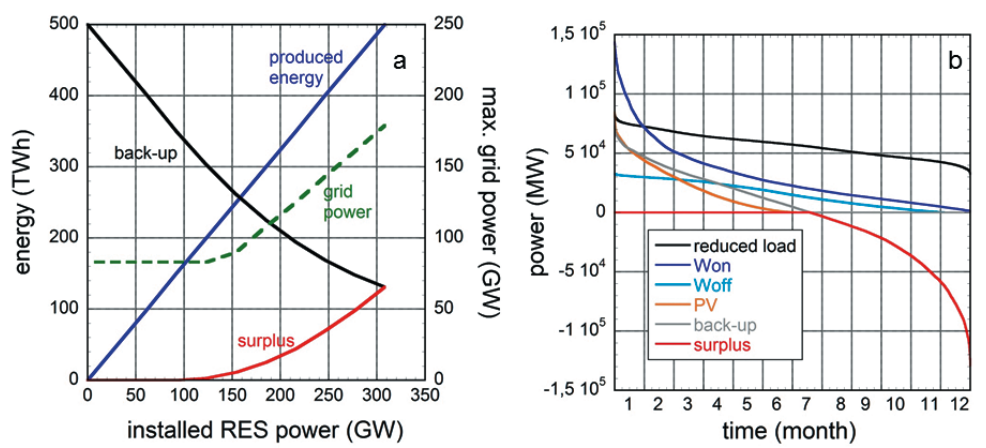

Fig. 10. - a) Produced, back-up and surplus energy (left axis), grid power (right axis) versus the installed power of renewable energies for Germany. b) Annual duration curves of the constituents of a renewable energy system producing $100 \%$ of the demand under optimal mix conditions. Surplus power is plotted negatively.

sharply increase the surplus energy level at a moderate further reduction of the back-up need and may not be the economic way to avoid back-up power. The grid power increases for the $100 \%$ case by more than a factor of 3 compared with the load stressing the need to limit the power peaks by input regulation.

Figure 10b shows the annual duration curves of the constituents of a RE system producing $100 \%$ of the demand under optimal mix conditions. The peak back-up power stays somewhat below the peak load; the maximal surplus power (plotted negatively) increases above the level of the load. If this has to be avoided and the level may not increase above peak-load, RES have to be disconnected from the grid during peak supply periods which add up to about half a month of losses which reduces system economy, however. PV is not available for half a year. Offshore wind matches somewhat the shape of the load; with the assumptions of this study, in the sum, offshore wind power does not contribute during about one month. Table I summarises the major system parameters for the $100 \%$, optimal mix case.

TABLE I. - Major system parameters for the 100\%, optimal mix case for Germany.

\begin{tabular}{|l|}
\hline$P_{W o n}=175 \mathrm{GW} ; P_{W \text { off }}=33 \mathrm{GW} ; P_{\mathrm{PV}}=97 \mathrm{GW} \rightarrow P_{\mathrm{RE}}$ installed \\
\hline$P_{\text {load }}=83 \mathrm{GW} ; P_{\text {back-up }}=73 \mathrm{GW}$ \\
\hline$W_{W \text { on }}=271 \mathrm{TWh} ; W_{W o f f}=135 \mathrm{TWh} ; W_{\mathrm{PV}}=94 \mathrm{TWh} ; W_{\mathrm{RE}}=500 \mathrm{TWh}$ \\
\hline$W_{\text {back-up }}=131 \mathrm{TWh} ; W_{\text {surplus }}=131 \mathrm{TWh}$ \\
\hline$f l h_{\text {back-up }}=1795 \mathrm{~h} ; c f_{\text {back-up }}=0.2$ \\
\hline
\end{tabular}




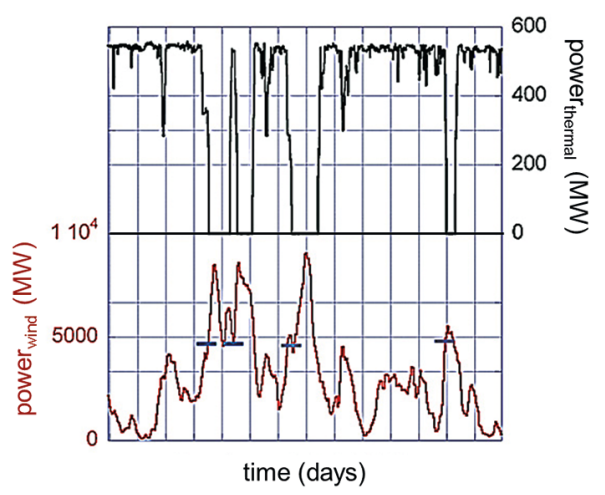

Fig. 11. - Upper trace: power of the $550 \mathrm{MW}$ Rostock coal power station; lower trace: wind power in the region of the German transmission network operator 50Hertz. Data are plotted for the $3 \mathrm{rd}$ and 4 th week in 2010.

\section{5. - The operation of the back-up system}

In the following, we will address the operation of the back-up system consisting of thermal power stations. With conventional supply, the supply system has to be regulated between the base and the peak load in a rather predictable fashion. The power gradients are small and easily manageable. With intermittent sources the thermal supply system has to cover the full power range from zero to nearly the peak load. The system dynamics increases strongly. This has been documented in detail in [16] and will not be repeated here.

Figure 11 shows the operation of the Rostock coal burning power station during the 3rd and 4th week in $2010\left(^{5}\right)$. The maximal power of this station is $550 \mathrm{MW}$. It is situated right at the Baltic Sea in one of the major wind production areas of Germany. Electricity transmission network operator in this region is 50Hertz [11]. The right ordinate shows the power variation of the thermal station (shifted origin) and the left one the wind power produced by 50 hertz. The two curves are correlated with $R=-0.85$ because the coal station is operated to supplement wind power and to regulate the grid conditions. The operational range is now from 0 to the maximal power. The horizontal bars indicate the wind power level where the coal station has to be turned down. Because of material fatigue this mode of operation causes a higher level of maintenance specifically when the number of cold starts increases. Also the amount of $\mathrm{CO}_{2}$ production increases typically by $5 \%$ if the same amount of energy is produced by steady-state or alternatively by fluctuating operation.

Now, we present the situation for the $100 \%$, optimal mix case based on the 2012 data. In fig. 12, the load, the balancing power of the back-up system and the surplus power are plotted for the period 9.1.-12.2.2012. The interplay between phases of surplus and

$\left({ }^{5}\right)$ www.kraftwerk-rostock.de 


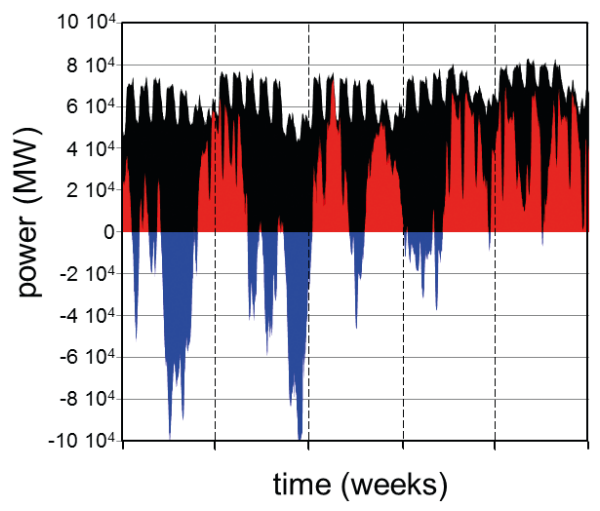

Fig. 12. - Load (black), back-up (red) and surplus power (blue) for the 100\%, optimal mix case for the five weeks 9.1.-12.2.2012.

those of shortage and the strong dynamics of the balancing power from zero level up to nearly the peak load are documented. The back-up power reaches nearly peak-load and only $12 \%$ saving in capacity is possible.

\section{6. - Storage}

Ultimately, the back-up system has to be replaced by storage. The data of fig. 12 allow us to easily assess the order of magnitude of a storage system. We add to a predefined storage content the surplus or subtract the back-up energy if the respective quantity is finite and the storage is not full or empty, respectively. Figure 13 shows the result for the same period, 9.1.-12.2.2012. At the end of this period, after $181 \mathrm{~h}$ consuming $7.1 \mathrm{TWh}$, the storage is empty. In order to avoid this for the whole year, a storage capacity of numerically $33 \mathrm{TWh}$ is necessary. The present storage capacity in Germany is about $50 \mathrm{GWh}$ realised largely by pumped water storage. It is clear from these figures that this technology cannot be scaled to the future needs of Germany. A totally new technology has to be developed most probably on the basis of chemical storage using hydrogen (from electrolysis) and $\mathrm{CO}_{2}$ to produce methane or higher carbon hydrides [17]. A comparison with the refinery investment realised in Germany allows to grasp the extent of necessary chemical production technology. German refineries can produce 2.1 Mill barrels of gasoline per day which adds up to 3 TWh per year - a factor of 10 lower than the principally necessary storage capacity. Another problem for chemical storage will be to handle the high power level at which surplus energy accrues. This requirement leads us to consider the expected system economy. The energy, the storage handles during the year is in the range of $131 \mathrm{TWh}$; its power capability is at the level of the surplus power $\sim 130 \mathrm{GW}$. Formally, $f l h=256 \mathrm{~h}$ which is by far too short to be economic by any means. For seasonal storage, a large chemical complex is needed without expectation of economic use. A mix of short- and longer-term storages may allow reducing the overall 


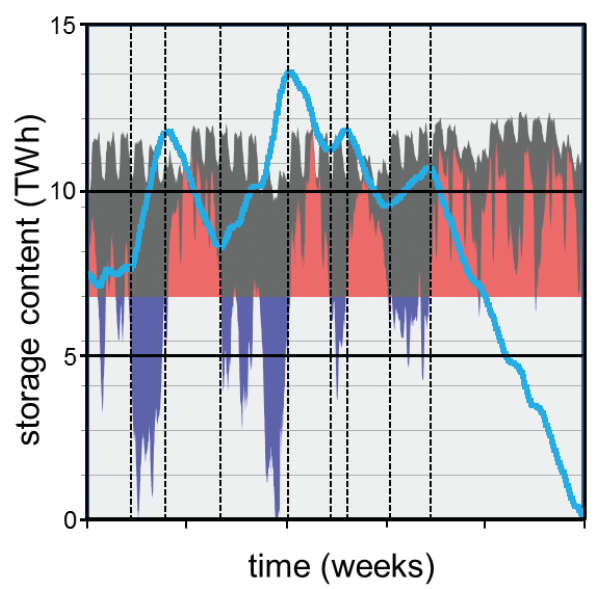

Fig. 13. - The variation of the storage energy content is plotted versus time for the same period as in fig. 12 (9.1.-12.2.2012) with fig. 12 as background. The dashed vertical lines separate the periods with back-up from those with surplus power.

storage capacity. Figure 14 plots the back-up energy normalised to the total demand (500 TWh) versus the storage capacity normalised in the same way. With increasing storage capacity, the back-up contribution reduces. Already a small storage downsizes the back-up need substantially whereas large capacities close to the nominal limit of $33 \mathrm{TWh}$ are rather inefficient. Therefore, the strategy has to be to split the task (and

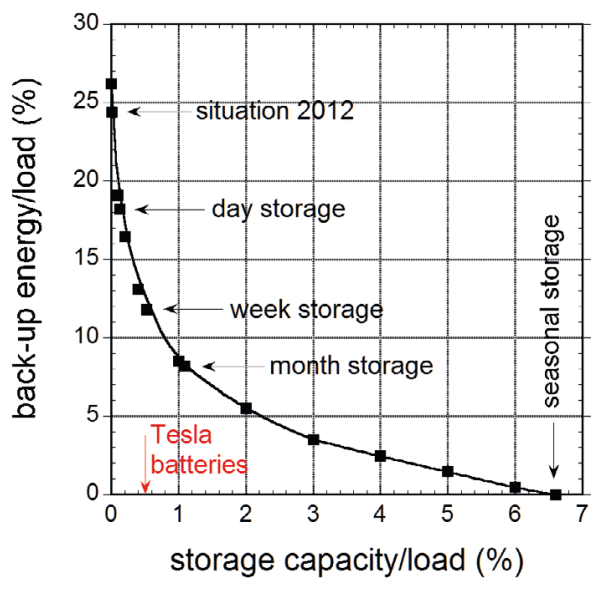

Fig. 14. - Normalised back-up energy versus storage capacity. The black arrows indicate the effect on the reduction of back-up energy due to the present available storage in Germany $(50 \mathrm{GWh})$, a daily, weekly, monthly and seasonal storage; the red arrow indicates the storage composed of all German cars equipped with Tesla Model $S$ car batteries. 


\section{EPJ Web of Conferences}
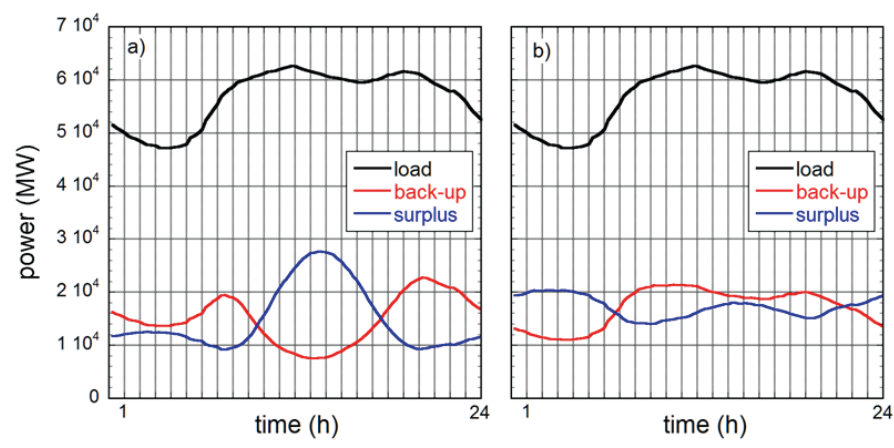

Fig. 15. - a) Annually averaged load, back-up and surplus power of a day for the $100 \%$, optimal mix case. b) as a) but with wind power replacing the photovoltaic share.

possibly the technology) in short- and long-term storage. Nevertheless, there cannot be any illusion about the size even of short-term storage. Also a daily storage needs a capacity of $640 \mathrm{GWh}\left({ }^{6}\right)$. Storages which cover a week $(2.6 \mathrm{TWh})$ or a month $(5.5 \mathrm{TWh})$ are also indicated in fig. 14. For comparison the capacity of the much debated secondary use of car batteries as storage is also given. If we assume that the 43.9 Mill cars which are presently on German roads are all electric and equipped with the battery of Tesla Model $S$ cars, the total storage capacity is about $2.6 \mathrm{TWh}$, which represents a weekly storage. Of course, the actual allocation of such a storage with parasitic use may only be a fraction of the maximal capacity, quoted here.

Other analogies to understand the size of required storage is the gas storage capability of Germany of about $200 \mathrm{TWh}$ which would provide $100 \mathrm{TWh}$ electricity assuming $\eta_{\mathrm{el}}=$ 0.5. As the necessary gas storage infrastructure is obviously available, the problem of storage is predominantly the problem of methane production in sufficient quantities at low costs.

Large scale chemical storage is still an R\&D field with uncertain outcome. For a long period, the rationale behind this development will be challenged by the availability of much cheaper natural gas.

\section{7. - Demand-side-management (DSM)}

This term "demand-side-management" denotes the strategy to shift the energy use from high-demand and therefore high-cost periods into low-demand and -cost periods. The classical — but simplistic — example is that a smart grid recognises a low-cost phase and turns on the home washing machine during the night. A first approach to the possibilities and limits for this concept is to identify the high- and low-cost periods during a day. Even when DSM becomes reality, by and large the private and economic

$\left({ }^{6}\right)$ Defined via the average value of the net daily surplus. 


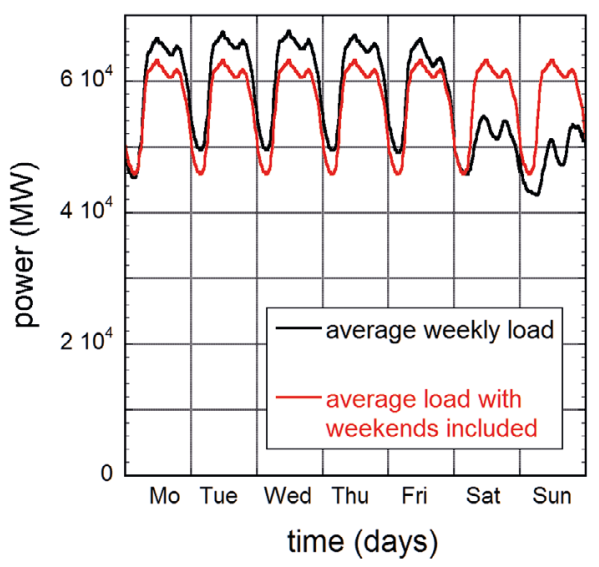

Fig. 16. - Annually averaged load during a week with the typical lowering during the week-end (black) and - in red — when the weekends are not discriminated and the year is composed of 365 days with identical load. For both curves, the consumed energy is $500 \mathrm{TWh}$.

activities will maintain the periodicity of the diurnal cycle. Therefore, we start with the daily variation of load, surplus and back-up powers averaged over the year. These three parameters are plotted in fig. 15a for the 100\%, optimal mix case. The surprising outcome is that the period with surplus $S>$ back-up $B u$ occurs during the day. If we associate the conditions $S>B u$ with the low-cost period for electricity, the consequence of DSM will be to enhance the economic activities during the day $\left({ }^{7}\right)$. This might indeed happen; in the last years, the day-night price difference of electricity at the European Energy Exchange decreased from 8 to $5 € / M W h$. The reason for this shift is the PV contribution during the day with maximal input during noon time. Figure 15b shows the same case but with the PV energy contribution replaced by wind. Now, we have the expected situation that surplus is larger during the night (because the load is smaller). Of course, in the summer season, the PV effect is even larger. Analysing only the winter period (October-March) the day splits into four periods, two of them with $S>B u$, two with $S<B u$. Again, this does not seem to be an attractive constellation.

At present, DSM is not implemented in large scale and the required technology is not yet installed. Nevertheless, the large PV input during noon is already affecting the prices structure, lowering the spot market electricity prices in this period with the consequence that peak load supply systems (gas turbines, pumped storage) do not find economic conditions any longer.

One could consider employing a diurnal storage which is able to move the electricity gain during the day (from 9:30 to 7:30) into the night. A storage of 0.9 TWh could thus

$\left({ }^{7}\right)$ And it would affect the concept to use car batteries for storage. Globally seen, they need to be charged during the day when they are in use, however. 


\section{EPJ Web of Conferences}

transfer a total of $64 \mathrm{TWh}$ during 223 days, half of what is needed. Whereas the average daily transfer is $0.28 \mathrm{TWh}$, the day-to-day variation is large with a standard deviation of $0.22 \mathrm{TWh}$. It is unclear whether a consistent use of the transfer is useful and economic facing this strong variability.

An easy but not simple step in the frame of DSM would be to spread out the economic activities fully into the weekends and to use the available wind and solar power. The benefit can be assessed by changing the weekly load pattern from the actual one to an artificial one as shown in fig. 16. which does not discriminate between working days and weekend. The annual electricity demand is kept constant at $500 \mathrm{TWh}$. As shown in fig. 16, the average peak load reduces from 68 to $63 \mathrm{GW}(7 \%)$; additionally, $7.5 \mathrm{TWh}$ can be used from RES. To use the weekends might be the most simple and effective form of DSM.

\section{8. - On the European-wide use of RES}

In the same way as for Germany, onshore wind $\left({ }^{8}\right)$ and partially PV data were processed for the following eight countries: Belgium (wind), the Czech Republic (wind and PV), France (wind and PV), Denmark (wind), Germany (wind and PV), Ireland (wind), Spain (wind and PV), and the UK (wind). These eight countries could be considered as representative for the supply of Europe with RES. They hold $60 \%$ of the consumption and engage $70 \%$ of wind and $55 \%$ of PV power of EU-28. In any case, the national RE supply technologies will be predominantly selected according to the strength of the natural sources and not all countries enjoy the conditions to produce both wind and PV power. Details of the analysis and reference to the data sources are given in ref. [18].

Two options have been considered:

1) Operation with the national RE-field composed from the national wind and where available - PV field scaled to the $100 \%$ limit. With solar contribution, wind and PV are split according to the optimal mix as shown in fig. 9a. for each of the four countries.

2) Operation with the EU-wide wind and PV field composed from the superposition of the national contributions assuming instant availability (cooper plate model).

With the EU-wide RE-field it is expected that the supply situation is eased because the spatial averaging will reduce the temporal fluctuations. Figure 17 compares the loads, the wind and PV powers for Germany (dashed curves) with the average wind power of the 8 countries (8-C) where wind is available and the average PV power of the 4 countries (4-C) where PV is available (solid lines). The results are plotted in the form of annual duration curves. For each case the energy produced (represented by the area beneath each curve) is normalized to 1 TWh to allow comparison.

$\left({ }^{8}\right)$ Offshore wind is not considered because the EU data base is still rather scarce. 


\section{LNES 2014}

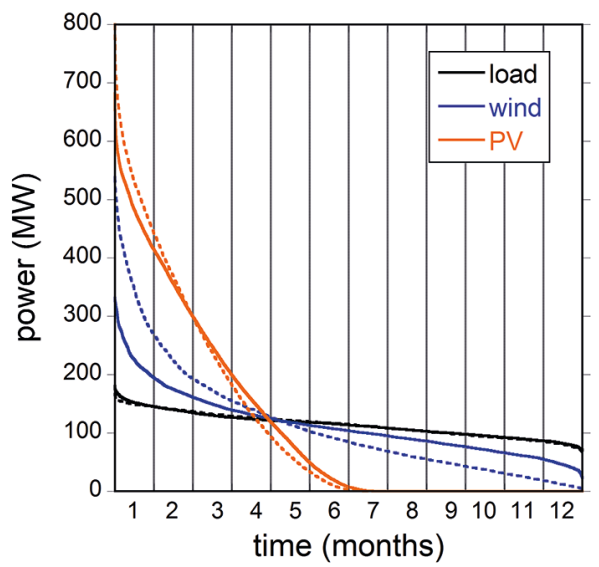

Fig. 17. - Annual duration curves for the load, wind and photovoltaic power for Germany (dashed curves) and the average power of the 8 countries (8-C) for load and wind and for PV of the 4 countries (4-C). Each curve represents an energy of 1 TWh.

There is hardly a difference between the German load and the average of the 8 countries in the shape of the load-curve indicating a rather homogenous electricity demand of these European countries which are part of a fairly unified market. The German PV field is in rough agreement with the average EU-wide PV field of the 4-C case. On the contrary, wind shows a much larger difference owing now to the averaging effect inherent to summing up several time series resulting from turbulent processes of different degrees of correlation. The averaging effect reduces the high-power and increases the low power values of the duration curve. In conclusion, the joint use of the European RE-field leads to the expected averaging effect which is, however, mostly originating from the wind component.

Operating with the EU-wide field instead of the national one leads to the following benefits: The back-up energy is reduced by $24 \%$, the maximal back-up power by $9 \%$, the maximal surplus power by $15 \%$, the maximal grid power by $7 \%\left({ }^{9}\right)$, the typical grid fluctuation level by $35 \%$ and the maximal storage capacity by $28 \%$ [18]. All values are averages of the 8 countries considered.

The realisation of the copper plate situation for the exchange of electricity in Europe needs the necessary grids inside the countries, mostly oriented north-south (because wind is more in the north and the consumers are often situated in the south) and the necessary interconnections to grids with typically east-west orientation. As the wind pattern over Europe is of the size of Europe itself, the benefit of connections to the immediate neighbours is of restricted potential: when a country produces surplus, also its neighbours are likely to produce it. Seen from Germany, Spain and Ireland are the

$\left({ }^{9}\right)$ This parameter strongly varies from country to country. 


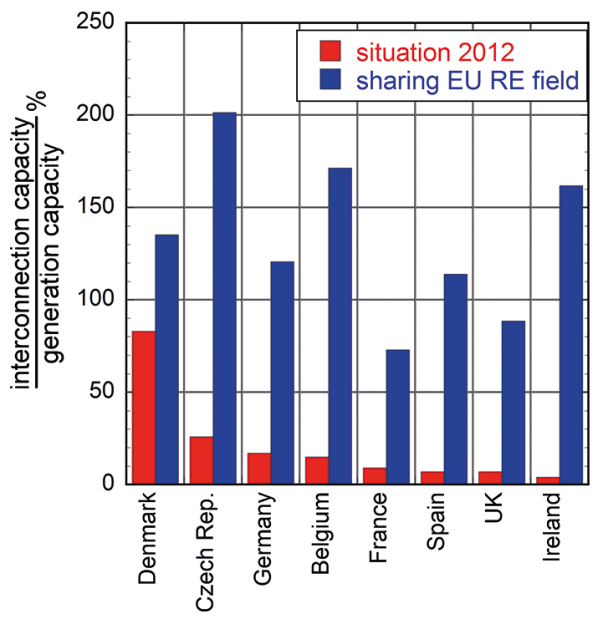

Fig. 18. - Interconnection capacity for the 8 countries considered normalised to the peak load for each case. The $100 \%$ case is compared with the present installations.

best partners for electricity exchange because their wind fields are least correlated to the German one with the consequence that their surplus shares are largest in periods where Germany is in need of and operates with back-up power.

The development of an east-west grid over Europe will be a tremendous task. The interconnectors for the cross-border electricity flow have to be able to handle the power level of the surplus power because it is the one which has to be distributed. The power capacity of the transmission system of the countries studied here is shown in fig. 18 in comparison to the present state of realisation [23]. The normalisation is the respective peak power value of the load. As different power levels exist for import and export, the respective maximum value is plotted in fig. 18 because sharing the EU-wide RE field requires transmission in both directions. Generally, the export power capacity is larger than the import one. In most cases the level of interconnection capacity is larger than the respective load.

Details of the national supply situation with RES are given in table II. Load [19] and hydro-electricity production [20] are taken from the literature. The required power capacity to be installed is calculated using tabulated $f l h$ values [18,21]. Surplus energy is obtained in the same fashion as shown for Germany in fig. 10. It is the author's arbitrary judgement, which countries may or may not invest into PV or offshore wind facing their climatic and geographic realities. The following total installations are necessary: onshore wind: $819 \mathrm{GW}$, offshore wind: $128 \mathrm{GW}$ and PV power $325 \mathrm{GW}$. The total surplus energy is $625 \mathrm{TWh}$. These figures can be qualified in the following way. The total area, necessary for onshore wind is about $500000 \mathrm{~km}^{2}$ at a typical power density of $2 \mathrm{~W} / \mathrm{m}^{2}$ [10]; the area necessary for the PV system is about $40000 \mathrm{~km}^{2}$ at a typical power density for the installation of large PV arrays of $10 \mathrm{~W} / \mathrm{m}^{2}$ [10]. The total area corresponds to that of France, the largest country in Western Europe. The surplus energy corresponds to the 
TABLE II. - The table lists the demand and the hydro-electricity production along with the calculated values of onshore (Won), offshore (Woff) and PV power for $100 \%$ electricity production by RES. The produced surplus energy is also given. It is the author's arbitrary judgement, which countries may or may not invest in PV or offshore wind facing their climatic and geographic realities. The power values are calculated from the energies in the three supply channels (according to the optimal mix and the assumed splitting of wind energy ( $2 / 3$ Won, $1 / 3$ Woff)) and the flh values (for details and references: see [18].)

\begin{tabular}{|c|c|c|c|c|c|c|}
\hline & Demand & Hydro-electricity & $P($ Won $)$ & $P(W o f f)$ & $P(\mathrm{PV})$ & Surplus \\
\hline Country & TWh & TWh & GW & GW & GW & $\mathrm{TWh}$ \\
\hline Austria & 70 & 37.7 & 16 & 0 & 5 & 7.2 \\
\hline Belgium & 82 & 2 & 37 & 8 & 0 & 18.0 \\
\hline Bulgaria & 32 & 3.2 & 15 & 0 & 5 & 6.5 \\
\hline Croatia & 17 & 5.2 & 6 & 0 & 2 & 2.7 \\
\hline Cyprus & 4 & 0 & 2 & 0 & 1 & 0.9 \\
\hline Czech Rep. & 68 & 2 & 39 & 0 & 13 & 17.2 \\
\hline Denmark & 34 & 0 & 10 & 3 & 0 & 9.0 \\
\hline Estonia & 8 & 0 & 3 & 1 & 0 & 2.1 \\
\hline Finland & 84 & 12.6 & 30 & 6 & 0 & 18.9 \\
\hline France & 485 & 65 & 100 & 29 & 89 & 94.5 \\
\hline Germany & 530 & 20 & 173 & 33 & 106 & 114.8 \\
\hline Greece & 50 & 4 & 19 & 0 & 7 & 10.3 \\
\hline Hungary & 39 & 0.2 & 22 & 0 & 8 & 8.7 \\
\hline Ireland & 26 & 1 & 6 & 2 & 0 & 5.6 \\
\hline Italy & 316 & 43.2 & 119 & 0 & 39 & 61.4 \\
\hline Latvia & 7 & 3.1 & 1 & 0 & 0 & 1.1 \\
\hline Lithuania & 11 & 0.4 & 4 & 1 & 0 & 2.7 \\
\hline Luxembourg & 6 & 0.1 & 3 & 0 & 0 & 1.4 \\
\hline Netherlands & 111 & 0.1 & 33 & 9 & 0 & 29.3 \\
\hline Norway & 128 & 123.6 & 1 & 0 & 0 & 1.1 \\
\hline Poland & 145 & 2.4 & 60 & 12 & 0 & 37.9 \\
\hline Portugal & 49 & 6.8 & 14 & 3 & 6 & 9.5 \\
\hline Romania & 52 & 15.3 & 17 & 0 & 6 & 8.3 \\
\hline Slovakia & 27 & 4.4 & 12 & 0 & 4 & 5.9 \\
\hline Slovenia & 13 & 4 & 4 & 0 & 2 & 2.0 \\
\hline Spain & 260 & 35 & 46 & 15 & 34 & 50.6 \\
\hline Sweden & 140 & 64.5 & 26 & 6 & 0 & 19.9 \\
\hline Switzerland & 65 & 35.3 & 15 & 0 & 5 & 6.7 \\
\hline UK & 320 & 5 & 57 & 20 & 66 & 70.9 \\
\hline Sum & 3179 & 496 & 819 & 128 & 325 & 625 \\
\hline
\end{tabular}




\section{EPJ Web of Conferences}

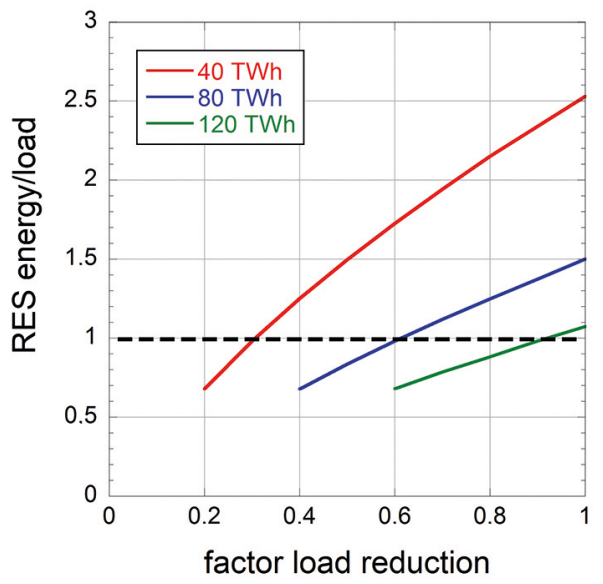

Fig. 19. - Normalised renewable energy necessary to meet the complete demand along with biomass (parameter of the curves) versus the factor to which the load has to be reduced to meet the complete supply by RES. At present biogas is used to produce $\sim 40 \mathrm{TWh}$ of electricity in Germany.

consumption of Germany plus Poland. With today's prices for wind and PV power, the European-wide wind and PV power of table II would cost 900 bn€ for onshore wind, $300 \mathrm{bn} €$ for offshore wind and $400 \mathrm{bn} €$ for $\mathrm{PV}$. The assumption is that onshore wind and $\mathrm{PV}$ power cost $1 € / \mathrm{W}$ and offshore wind costs $2 € / \mathrm{W}\left({ }^{10}\right)$ installed power [22]. All these figures vary from country to country and will change in course of time and represent rough guidelines only. The costs for the electricity collection and distribution infrastructure, the operation of the back-up systems, and the installation of storage systems are not considered.

\section{9. - Limits for the use of RES}

There may be technical limits for the use of RES - e.g. insurmountable obstacles in the large-scale development of chemical storage, or economic limitations - e.g. in connection with intermittent component operation, or societal resistance - e.g. resistance against the deployment of wind turbines or HV-grids.

Figure 14 tells us that it might not be sensible to meet the electricity demand by $100 \%$ RES necessitating storage because high capacities do not pay off. It might be better to meet the final demand by either electricity import or allowing for lower $\mathrm{CO}_{2}$-emitting gas burning conventional power stations.

Figure 10 shows for Germany inter alia the development of surplus energy and the one of the grid power and indicates that below a $40 \% \mathrm{RE}$ contribution the technical

$\left({ }^{10}\right)$ More realistic may be $3 € / \mathrm{W}$; the present costs of the Gwynt y Mor offshore wind park is about $3.5 € / \mathrm{W}$. 
problems can be handled without extreme technical risks and inflated costs. In this range the demand mostly absorbs the intermittent power. Therefore, $40 \%$ intermittent power might be tolerable target $\left({ }^{11}\right)$.

Using biomass for electricity generation, which we discarded in this paper, and reducing the consumption, the $100 \%$ target can indeed be met. Figure 19 plots the relation between the RE fraction and the reduction of the demand from the $500 \mathrm{TWh}$-level for three cases we assumed - the use of 40 TWh biomass for electricity production, twice and three-times this amount. At present, about 40 TWh biomass are used to generate electricity in Germany. In this case, a 100\% supply with RES requires a reduction in consumption to $30 \%$ of the present one. No reduction in consumption is required with $40 \mathrm{TWh}$ biomass contribution for a RE production of 2.5 times the annual need. Facing the general limitations in the use of biomass [9] it is difficult to see how its share can be substantially increased to reduce either the restrictions on consumption or the extension of surplus energy production.

\section{0. $-\mathrm{CO}_{2}$ emission}

One reason for changing from fossil fuels to RES is to reduce the emission of $\mathrm{CO}_{2}$. Figure 20 shows the reduction of the specific emission factor $\eta_{\mathrm{CO}_{2}}$ (specific $\mathrm{CO}_{2}$ production related to electricity generation) versus the fraction of RES in the electricity mix under the optimal mix case for Germany $\left({ }^{12}\right)$. Two limits are considered: 1 ) production of the residual power by the present mix of fossil fuels (replacing the nuclear production by fossil fuel with the present mix) and 2) by using gas alone. The results are compared with specific $\mathrm{CO}_{2}$ production data of various countries.

$\eta_{\mathrm{CO}_{2}}$ decreases with increasing $\mathrm{RE}$ share. The gas-only curve is lower because $\eta_{\mathrm{CO}_{2}}=0.411 \mathrm{kgCO} 2 / \mathrm{kWh}$; the black curve starts with $\eta_{\mathrm{CO}_{2}}=0.874 \mathrm{kgCO}_{2} / \mathrm{kWh}$ which represents the specific emission factor when the full German demand is produced by fossil fuels in the ratio the present mix. The remaining part at $100 \%$ RE-fraction reflects the production of $131 \mathrm{TWh}$ back-up power. A further reduction in $\eta_{\mathrm{CO}_{2}}$ is possible with storage and $\mathrm{CO}_{2}$ emission becomes zero at a nominal storage capacity of $33 \mathrm{TWh}$. Figure 20 demonstrates the effect of using gas instead of a mix with substantial shares of coal and lignite $\left({ }^{13}\right)$. A reduction of by $\eta_{\mathrm{CO}_{2}}=0.1 \mathrm{kgCO}_{2} / \mathrm{kWh}$ corresponds to the increase of the RE fraction by $15 \%$.

These two limiting curves are compared with national values [24] represented by

${ }^{11}$ ) This limit varies between the 8 -C from $\sim 30 \%$ to $\sim 50 \%$ and depends on the $f l h$ values of the respective RES mix.

$\left.{ }^{(12}\right) \eta_{\mathrm{CO}_{2}}$ values are referred to the production of electricity in $\mathrm{kWh}$ and not to the burning of fossil fuels. The following values are used: $\eta_{\mathrm{CO}_{2}}^{\text {coal }}=0.902 \mathrm{kgCO}_{2} / \mathrm{kWh}, \eta_{\mathrm{CO}_{2}}^{\text {lignite }}=1.161 \mathrm{kgCO}_{2} / \mathrm{kWh}$, $\eta_{\mathrm{CO}_{2}}^{\text {gas }}=0.411 \mathrm{kgCO}_{2} / \mathrm{kWh}$. These values are based on the fuel emission factors and the average thermal efficiency for each type of power plants.

$\left({ }^{13}\right)$ The use of shale-gas in USA leads to a strong reduction of $\mathrm{CO}_{2}$ emission whereas the use of RES in Germany has the indirect consequence of a strong $\mathrm{CO}_{2}$ emission increase. 


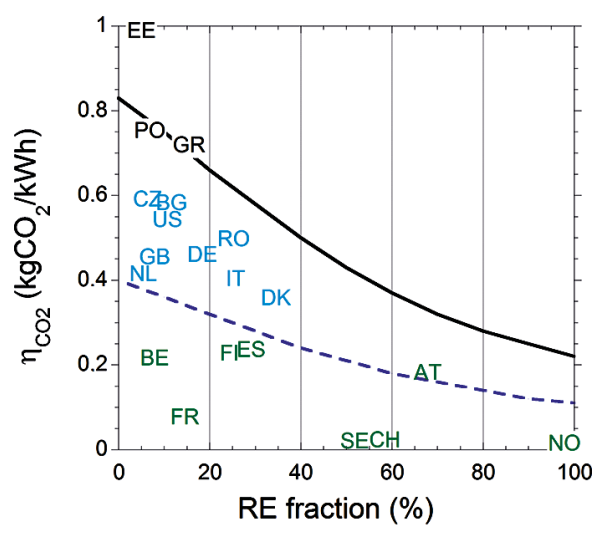

Fig. 20. - Specific $\mathrm{CO}_{2}$ emission factor for electricity generation of Germany under the optimal mix case versus wind and PV energy normalised to the load for two cases: 1) the back-up energy is produced exclusively by the 2012 mix of fossil fuels of Germany (solid curve) or 2) it is produced by gas alone (dashed curve). The symbols indicate the situation of European countries denoted by their official country code. The RE fraction is defined by the ratio of the energy from wind, PV and hydropower divided by the electricity consumption. The black symbols denote countries which burn mostly coal, the green ones countries with a supply based predominantly on nuclear and hydro electricity.

country codes in fig. 20. The RE factor is determined from wind, PV and hydroelectricity. The German value (DE) is below the upper curve because of nuclear and RE contributions but still above the curve for gas. Below the gas-curve are countries which massively use hydro- and nuclear electricity. France, Sweden, Switzerland and Norway have low levels, which cannot be achieved by $100 \%$ RES and the remaining back-up generated by gas power stations. This quality can only be met alternatively by employing $\mathrm{CO}_{2}$ free storage. It has to be taken note of those countries which have already reached the low $\mathrm{CO}_{2}$ emission goal today targeted by other countries for 2050 and the environmental quality in electricity generation by the mix of hydro- and nuclear power.

A closer look into the structure of the 19 data from the different countries shows a clear increase of $\eta_{\mathrm{CO}_{2}}$ with the fossil fraction and a clear decrease with the $\mathrm{CO}_{2}$ free fraction. For both cases the correlation coefficient is about 0.9. The analysis for the different constituents of the $\mathrm{CO}_{2}$ free generations shows that $\eta_{\mathrm{CO}_{2}}$ decreases with growing hydro- and nuclear production with $R=0.67$ or 0.41 respectively, but does not show much of a variation with the wind $+\mathrm{PV}$ fraction. For this case, $R=0.05$.

\section{1. - Electricity costs}

In the final section we address the electricity cost situation first for Germany. As fig. 21 documents, the electricity prices for Germany continuously rose in the period from 2008 to 2013 whereas the trading price for electricity (spot market price) showed the tendency to decrease. The increase reflects the rise of taxes and other charges on 
LNES 2014

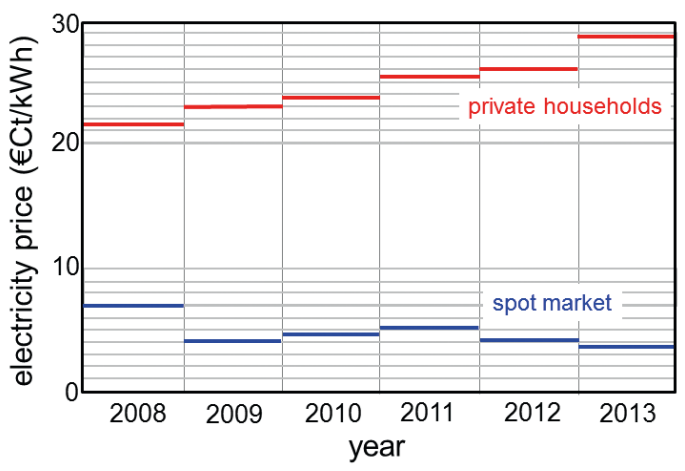

Fig. 21. - Development of the average electricity price in Germany for households and at the spot market.

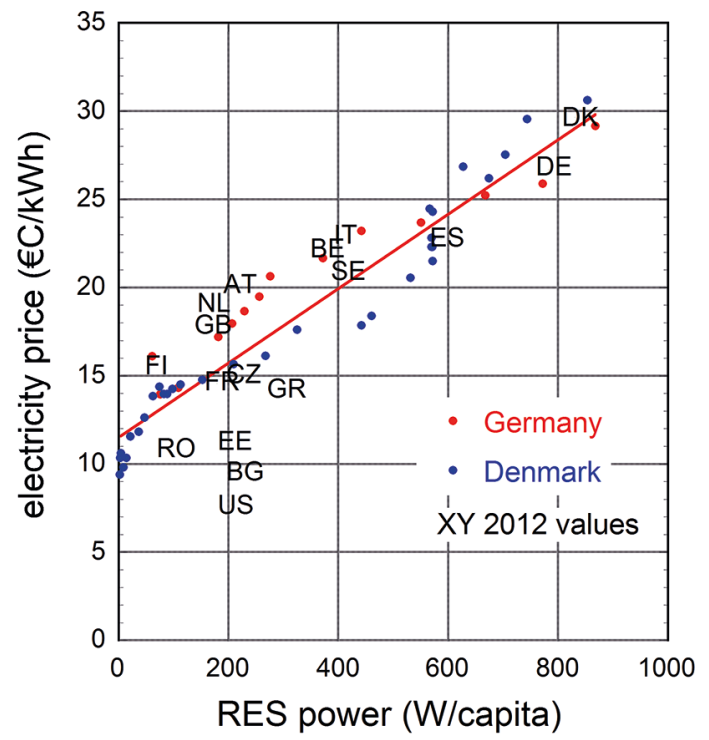

Fig. 22. - Electricity price versus the fraction of renewable energies normalised against the population of various European countries in 2012 (denoted by country code). For Denmark and Germany, the development of the electricity price is compared to that of installed RE power.

the electricity price; the spot-market price decrease is affected by the drastic increase in electricity production capacity thanks to the deployment of RE sources. The gap between the prices is startling. One of the charges for the household prices in Germany are the costs of the feed-it-tariff system, which subsidizes the RE build-up with its strong increase in the last years. In 2014, it adds $6.24 € \mathrm{C} / \mathrm{kWh}$ to the electricity price, which makes the German price one of the highest in Europe.

Figure 22 shows the relation between electricity prices versus installed RE power 


\section{EPJ Web of Conferences}

normalised to the respective population $\left({ }^{14}\right)$. The price development is shown for Germany and Denmark over the period of major RE installations and for 17 countries in 2012. The fit to the data indicates a linear increase starting from an offset of the form $y=11.52(€ \mathrm{C} / \mathrm{kWh})+0.021 x$. The diagram ends at $1000 \mathrm{~W} /$ cap. The $100 \%$, optimal mix case corresponds to $3825 \mathrm{~W} /$ cap for Germany. Of course, the linear variation will not hold up to this limit but the relation indicates the costs for the consumer if RES are built-up at a rate as demonstrated by Germany, Denmark and others.

\section{2. - Discussion}

Science and technology liberated mankind from many perils and the unpredictability of nature. The technology of wind and PV electricity supply does not provide this quality any longer unlike dispatchable power which allows demand and supply to match. Therefore, a complete supply by RES has drawbacks:

- the need to duplicate the system whereas thermal power ensures the availability of electricity when needed; its level is nearly independent of the installed RE power (12\% saving);

- the additional RE system requires high power capacities; Germany alone could supply Europe with electricity if all components operate at full scale;

- because of the low power density of the natural sources, a large area for wind and PV systems has to be provided; the character of landscape drastically changes thereby;

- large and expensive grid systems are necessary because the best sources for RES are not where the economic activities are located. The grid extension has to happen both at the high- and the low-voltage plane.

- the production of large amounts of surplus power which has to be wasted or exported at negative prices [16];

- large challenges for the technical integrity of the back-up system.

The technology change to RES in Germany and other countries is faster than any other energy system change in the past [26] and it is less prepared than other historic large-scale measures affecting the national infrastructure $\left({ }^{15}\right)$. The main reason is that the German "Energiewende" is a political project fuelled by large subsidies. This has consequences:

$\left({ }^{14}\right)$ The EU data have been provided by H. Poser, Finadvice [25].

$\left({ }^{15}\right)$ E.g. the introduction of $400 \mathrm{kV}$ grid voltage, high-voltage DC transmission or the technical challenges of the railway frequency $\left(16 \frac{2}{3} \mathrm{~Hz}\right)$ by new power electronics in Germany [27]. 
- There is a mismatch in the coherent realisation of all technical infrastructure components like electricity sources, grids $\left({ }^{16}\right)$ or storage systems. Storage technology still requires many decades of $\mathrm{R} \& \mathrm{D}$.

- The electricity price is high in the transitional period because the old system has to be financed as well as the new one. This might lead to losses in economic vitality specifically when competitors have access to cheep alternatives, e.g., USA with shale-gas.

- New economic models are not in place to ensure a fair market trading of electricity leading to low prices and incentives for innovations. This issue is a challenge because the intermittent nature of RES enforces all other components to follow their rhythm with the consequence of insufficient use of their respective capacity.

- New and attractive innovations may come too late because the major decisions have been taken prematurely risking island solutions.

- Obviously, subsidy does not allow the development of a sustainable economic basis as experienced by the collapse of the German solar industry.

The views expressed here might read rather negative. But others come to similar conclusions, e.g., Robert Bryce, Senior Fellow at the Center for Energy Policy and the Environment at the Manhattan Institute in his article: Maintaining the Advantage: Why the U.S. Should Not Follow the EU's Energy Policies [29]:

"To address the issues of carbon dioxide and climate change, the European Union in general and Germany in particular have rushed to impose mandates and subsidies for renewable energy upon the market. Those policies have resulted in dramatically higher energy costs. Meanwhile, thanks to ongoing innovation in the U.S. oil and gas sector and the profusion of natural gas that resulted from that innovation, the U.S. has reduced its carbon dioxide emissions more rapidly than the EU has, and it has done so at much lower cost. The lesson is clear: markets work, and they work best when governmental interventions are not excessive. U.S. policymakers must take a hard look at the experience of the EU and seek to avoid those same mistakes."

What could be done alternatively? In this paper, we conclude that about $40 \%$ of the demand could be absorbed by the grid and could therefore be a rational development goal. We have also shown the benefits of nuclear energy in keeping the electricity-caused $\mathrm{CO}_{2}$ production low. As there are countries in Europe where this energy form is accepted by society with the moral and practical benefit of low $\mathrm{CO}_{2}$ emission this technology should be further pursued. A mix of nuclear with hydro-electricity together with wind and PV power regulated by gas-power might be a reasonable splitting allowing a low

\footnotetext{
$\left({ }^{16}\right)$ Because of a severe lack of grids from North to South Germany, much of the electricity flows via Poland and the Czech Republic causing technical and economic problems for Germany's neighbors [28].
} 


\section{EPJ Web of Conferences}

$\mathrm{CO}_{2}$ emission level. Such a system would also be open for innovations irrespective of whether they affect dispatchable power, e.g. fusion or they represent advancements of RES. However, an EU-wide cooperative energy policy is necessary which is difficult to imagine facing the single-handed moves of European countries in their energy strategies up to now.

In its consequence, the change in energy supply technology corresponds to the replacement of chemical energy by electricity as primary energy form. In this paper, we have only concentrated on electricity generation by RES and have pointed out some of its specific features. But the electricity share is $\sim 25 \%$ of the total world primary energy consumption. A tremendous task is ahead of mankind and therefore, it is specifically correct not to put all eggs into one basket.

$$
* * *
$$

Contributions from P.-F. Bach, M. Hirsch and M. Wanner are gratefully acknowledged.

\section{REFERENCES}

[1] See contribution by H. J. Wagner in this volume.

[2] Würfel P., Physics of Solar Cells: From Basic Principles to Advanced Concepts (Wiley, 2009) ISBN: 978-3-527-40857-3.

[3] See contribution by Ripani in this volume.

[4] See contribution by Revol in this volume.

[5] See contribution by Ongena in this volume.

[6] See contribution by Manzella in this volume.

[7] See contribution by Schulze in this volume.

[8] See contribution by Prodi in this volume.

[9] Leopoldina, Statement: Bioenergy - Chances and Limits (2012); http://www . leopoldina. org/uploads/tx_leopublication/201207_Stellungnahme_Bioenergie_LAY_en_final_01.pdf.

[10] MacKay D., "Sustainable Energy - without the hot air", http://www.withouthotair. $\mathrm{com} /$.

[11] ENTSO-E country package: https://www.entsoe.eu/data/data-portal/country-packages/ www.50hertz.com/

ww. tennet.eu/de/home.html

www . amprion.net/

www.transnetbw.de/.

[12] http://www.bard-offshore.de/projekte/offshore/bard-offshore-1.html.

[13] www.alpha-ventus.de.

[14] Wagner H. J. and Mathur J., Introduction to wind energy systems-Basics, technology and operation (Springer Verlag), ISBN: 9783642329753.

[15] Erdmann G. and Zweifel P., Energieökonomik-Theorie und Anwendungen (Springer Verlag) 2008.

[16] Wagner F., Eur. Phys. J. Plus, 129 (2014) 20.

[17] See contribution by Schlögl in this volume.

[18] Wagner F., Eur. Phys. J. Plus, 129 (2014) 219.

[19] ENTSO-E, consumption data (2013); https://www.entsoe.eu/db-query/consumption/ monthly-consumption-of-all-countries-for-a-specific-year. 


\section{LNES 2014}

[20] Beurskens L. W. M. and Hekkenberg M., "Renewable Energy Projections as Published in the National Renewable Energy Action Plansof the European Member States" European Environment Agency report ECN-E-10-069. Lehner B., Czisch G. and Vassolo S., EUROPE'S HYDROPOWER POTENTIAL TODAY AND IN THE FUTURE", http://gc.transnational-renewables .org/wiki/images/8/8c/2002-01-16_ew_8 hydropower_low.pdf.

[21] Held A. M., "Modelling the future development of renewable energy technologies in the European electricity sector using agent-based simulation", dissertation KIT; http://www.google.de/url?sa=t\&rct=j\&q=\&esrc=s\&source=web\&cd=1\&ved= OCCcQFjAA\&url=http $\% 3 \mathrm{~A} \% 2 \mathrm{~F} \% 2 \mathrm{Fdigbib}$. ubka. uni-karlsruhe. de $\% 2 \mathrm{Fvolltexte}$

$\% 2$ Fdocuments $\% 2$ F $1809689 \&$ i=v8TDU-qyDOLA7AaH5IDYAg\&usg= AFQjCNFaErVpw8e9B18ETa97y0w_VA5jZQ.

[22] AGORA, "Studie zum kostenoptimalen Ausbau der Erneuerbaren Energien", Hintergrunddokument Kostenannahmen und Szenarien, BERLIN, 01.03.2013 http://www . agoraenergiewende.de/fileadmin/downloads/publikationen/Agora_Studie_ Kostenoptimaler_EE-Ausbau_Annahmen_Voraussetzungen_Praesentation.pdf.

[23] ENTSO-E System Adequacy Forecast 2012-2025 (database: 21.12.2011).

[24] IEA, http://www.energies-renouvelables.org/observer/html/inventaire/Eng/ sommaire. asp\#chapitre3.

[25] http://www.finadvice.ch/files/germany_lessonslearned_final_071014.pdf.

[26] Smil V., Sci. Am., 52 (2014) 52.

[27] Hosemann G., Friedrich-Alexander-Universität Erlangen-Nürnberg, private communication.

[28] Boldis Z., Europhys. News., 44/4 (2013) 16.

[29] http://www.manhattan-institute.org/html/eper_13.htm\#.VEoqqGP-SJA. 